\title{
A Novel Cognitive-Linguistic Approach to Addressing Developmental Reading Disorders: A Pilot Study
}

\author{
Eun Jin Paek ${ }^{\mathrm{a}}$, Laura L. Murray ${ }^{\mathrm{b}}$ \\ ${ }^{a}$ Department of Audiology and Speech Pathology, University of Tennessee Health Science Center, Knoxville, TN, USA \\ ${ }^{b}$ School of Communication Sciences and Disorders, Western University, London, ON, Canada
}

Correspondence: Eun Jin Paek, PhD Department of Audiology and Speech Pathology, University of Tennessee Health Science Center, Knoxville, TN 37996, USA

Tel: +1-865-974-5277

E-mail: epaek@uthsc.edu

Received: May 4, 2018

Revised: August 12, 2018

Accepted: August 26, 2018

\begin{abstract}
Objectives: Prior research indicates that individuals with developmental dyslexia can benefit from working memory (WM) training to improve reading skills. The effect of WM training using linguistic stimuli to additionally target reading processes, however, has not been explored yet. It is also unclear whether different cognitive-linguistic profiles lead to different treatment improvement and transfer patterns. Thus, the current study investigated the efficacy of a novel cognitive-linguistic treatment that utilizes word- and sentence-level stimuli with irregular spellings to address developmental reading disorders. Methods: One adolescent and one adult with developmental dyslexia participated and were trained with six types of basic and complex verbal WM tasks combined with strategy training. A singlecase experimental design was utilized to probe participants' responses to the treatment protocol over time. To delineate baseline cognitive-linguistic profiles and transfer effects, a battery of formal tests and probe tasks was administered at pre-treatment, post-treatment, and 6-week follow-up. Results: Both participants showed improved performance on the training tasks, but across participants different patterns of improvements were observed. Transfer effects were observed in terms of decoding, fluency, and reading comprehension, and perceived benefits were reported. These gains were maintained at the 6-week followup. Conclusion: The current findings suggest that cognitive-linguistic intervention yields beneficial effects for developmental dyslexia and provides empirical evidence for evidencebased practice of clinicians who work with adolescents and adults with developmental reading disorders.
\end{abstract}

Keywords: Developmental reading disorders, Intervention, Working memory, Language
Developmental reading disorders, including developmental dyslexia, are characterized by difficulties with fluent word recognition (i.e., decoding of words) and spelling; despite intact sensory abilities and adequate intelligence (Peterson \& Pennington, 2015). For the last several decades, a great deal of research has suggested that phonological deficits underlie these reading difficulties and dyslexia symptoms (i.e., the phonological deficit hypothesis; Lyon, Shaywitz, \& Shaywitz, 2003; Peterson \& Pennington, 2015). Accordingly, the main focus of intervention for dyslexia, and more broadly, developmental reading disorders has been bolstering phonological awareness and letter-sound knowledge, with research providing evidence that this approach might be effective for improving decoding skills, and reading rate and comprehension (National Reading Panel, 2000).

In addition to this phonological deficit hypothesis and its associated phonological intervention approach, it has been also proposed that decoding and reading not only demand phonological awareness and letter-sound knowledge, but also engage a multi- 
Eun Jin Paek, et al. • A Novel Cognitive-Linguistic Approach to Addressing Developmental Reading Disordeke

tude of other linguistic and cognitive processes (e.g., Lawton \& Shelley-Tremblay, 2017). Thus, several researchers have emphasized the influence of multiple neurocognitive factors on developmental reading difficulties (i.e., multiple deficit accounts; Duff \& Clarke, 2011; Peterson \& Pennington, 2015). One of these factors is working memory (WM) (Baddeley, 2003), our ability to maintain as well as manipulate a certain amount of information over a short period of time. That is, perceptual and linguistic information (e.g., grapheme and phoneme) must be maintained in WM for a certain period of time to support the active processing of reading (Alloway, Wootan, \& Deane, 2014). Likewise, reading difficulty can occur despite relatively intact phonological skills or representations (e.g., Valdois et al., 2003). For example, Valdois et al. (2003) examined a teenager diagnosed with developmental dyslexia who showed good phonological awareness despite substantial difficulties in reading and spelling.

Therefore, intervention approaches to enhance WM skills offer a credible option given that prior research has established that WM components such as the phonological loop, central executive, or both play an important role in reading and writing skills (Daneman \& Carpenter, 1980). There is also empirical support for the influential role of WM's phonological store in decoding, the negative influence of WM demands on dyslexia symptoms, and the frequent presence of verbal WM deficits in individuals with reading disabilities (e.g., Kibby \& Cohen, 2008).

Indeed, several studies to date have investigated the effects of WM training on reading performance in typically developing children and children with developmental reading disorders (e.g., Dahlin, 2011; Loosli, Buschkuehl, Perrig, \& Jaeggi, 2012; Luo, Wang, Wu, Zhu, \& Zhang, 2013; Maridaki-Kassotaki, 2002). These studies have varied with respect to the type of training tasks, participant characteristics, and transfer tasks, and consequently, their outcomes have varied. For instance, there have been inconsistent reports of WM training's transfer effects to reading performance, particularly in terms of decoding skills. Loosli et al. (2012) found increases in reading performance (i.e., reading aloud at text and word levels) after WM training in typically developing children, although there was no gain in reading pseudowords aloud; these researchers did not evaluate for changes in reading comprehension skills. Somewhat similarly, Dahlin (2011) observed improved reading comprehension skills after WM training in Swedish children with special needs, with no changes in the children's nonword decoding skills. Luo et al. (2013) also reported transfer effects in that children with dyslexia showed improvements on oneminute tests of reading words aloud after WM training. In contrast, both Horowitz-Kraus and Breznitz (2009) and Shiran and Breznitz (2011) reported that after WM training, university students with and without dyslexia showed reading improvements for both word and nonwords.

Despite the heterogeneity in study designs and participant characteristics, at least a few studies focusing on children with developmental dyslexia found improved reading and comprehension following WM training, suggesting that intervention to improve WM may help children become more proficient in decoding (Luo et al., 2013) and reading comprehension (Dahlin, 2011; Luo et al., 2013). In addition, initial research suggests that WM training can benefit reading skills in young adults with developmental dyslexia (Horowitz-Kraus \& Breznitz, 2009; Shiran \& Breznitz, 2011). Specifically, a group of college students trained with verbal and nonverbal WM tasks exhibited not only post-treatment increases in their verbal and visual-spatial spans, but also improved decoding, reading rate, and comprehension scores (Shiran \& Breznitz, 2011). Such treatment outcomes are in the same vein as the findings that WM training can yield transfer effects to a reading comprehension task in typical college students (Chein \& Morrison, 2010).

Thus far, however, most research has focused on young children or college students, leaving little to no investigation of whether WM intervention can evoke reading improvements in adolescents or other age groups with developmental reading disorders. Also there has been no inspection of individual responses to WM training, because previous studies averaged all participants' responses for a group comparison (e.g., Shiran \& Breznitz, 2011). As a result, possible differences between responders and non-responders have been obscured, leaving a need to delineate the profiles of treatment responders and non-responders, as well as to determine how to adapt interventions to suit each individual's needs (Duff \& Clarke, 2011). In addition, given the complex nature of reading tasks in our daily lives, it is conjectured that those who did not benefit from the previously mentioned training heavily focused on phonological aspects of reading (i.e., phonological awareness, or letter-sound 
correspondence) may exhibit positive outcomes from a cognitivelinguistic intervention that taps WM as well as phonological processes to address reading difficulties.

Therefore, the current study examined the benefits of a novel cognitive-linguistic training protocol, designed to stimulate both WM and language processing, on developmental reading difficulties using a single-case, multiple baseline experimental design (Tate, Perdices, McDonald, Togher, \& Rosenkoetter, 2014). We aimed to determine how two individuals, who demonstrate reading difficulties but differ in terms of their cognitive and linguistic strengths and weaknesses, respond to the same cognitive-linguistic training.

Our novel treatment approach targeted both WM and linguistic skills for three reasons: (1) individuals with developmental dyslexia or other reading disorders commonly have difficulties in both domains mentioned above; (2) the adolescent and adult participant in the present study, who already experienced training regarding phonics and basic phonological rules, reported plateauing of gains from and/or reduced interest and motivation with the traditional reading treatment approach (i.e., treatment focusing only on linguistic components); and, (3) treatment tasks with significant concomitant cognitive-linguistic demands should more closely relate to the complexity of daily reading tasks, and therefore be ecological valid and foster transfer effects. With respect to WM, our cognitive-linguistic intervention was designed to address both the central executive and phonological store components given that both impact a myriad of cognitive and linguistic processes including reading and writing (Baddeley, 2003; Dahlin, Bäckman, Neely, \& Nyberg. 2009). Although some researchers have argued that individuals with developmental reading disorders do not exhibit impairment in the central executive component of their WM (Kibby \& Cohen, 2008), findings from recent studies involving this population suggest impairment in both the phonological store and central executive components of $\mathrm{WM}$, rather than selective impairment of the phonological loop (e.g., Swanson, 1994; Varvara, Varuzza, Padovano Sorrentino, Vicari, \& Menghini, 2014). For example, individuals with developmental dyslexia have been found to demonstrate impairments on WM tasks that emphasize the central executive component (e.g., N-back, backward digit span), supporting that more global and higher-order cognitive deficits might be a crucial feature of dyslexia (Varvara et al., 2014)

In addition, because many treatment research studies regarding executive function, attention, and working memory have supported the use of strategy training to maximize treatment effectiveness in multiple clinical populations (Cicerone et al., 2011; Murray, 2012; O’Hara et al., 2007; Rebok, Carlson, \& Langbaum, 2007; Sohlberg, Ehlhardt, \& Kennedy, 2005), strategy training was included in our multi-component treatment protocol. Such previous studies have found that self-directed strategy training, particularly when strategies focus on fostering or supporting self-monitoring and control of cognitive processes (e.g., dual coding strategy or verbal rehearsal strategy), bolsters treatment gains in terms of both generalization and maintenance of treatment effects. Thus, our novel treatment approach was additionally designed to tap meta-cognitive processing by including strategy training within treatment sessions.

Given these complex mechanisms underlying developmental reading disorders and an interdependent relationship between WM and reading skills, we predicted that our novel intervention approach may yield positive outcomes if treatment activities targeted multiple aspects of language and cognition, particularly if individuals have already mastered elementary sound-letter knowledge or have not responded well to traditional interventions that emphasize phonological awareness (Al Otaiba \& Fuchs, 2006). Also, given that learning during simple tasks is unlikely to generalize toward complex tasks (Wulf \& Shea, 2002), we hypothesized that complex WM activities combined with phonologically challenging stimuli would foster improved outcomes in daily reading undertakings, which are frequently too complex. Lastly, we further predicted transfer to untrained tasks because our treatment included strategy training, a recommended approach to maximize generalization of treatment effects in both cognitive and language intervention practice guidelines (e.g., Cicerone et al., 2011; Sohlberg et al., 2005). Hence, our research questions were as follows:

1) Would our cognitive-linguistic intervention yield improvement in trained and untrained WM tasks?

2) Would our cognitive-linguistic intervention produce transfer effects to untrained tasks in language domains such as reading fluency and comprehension?

3) Would our cognitive-linguistic intervention yield different outcome patterns across two participants with different cog- 
Eun Jin Paek, et al. • A Novel Cognitive-Linguistic Approach to Addressing Developmental Reading Disorders

nitive and language profiles, and thus support the requisite for individualized treatment to meet the needs of the diverse population with developmental reading disorders?

\section{METHODS}

\section{Participants}

One adolescent (AR; 16 years old) and one adult (CR, 35 years old with a Bachelor's degree) participated. Both participants were male, right-handed, native speakers of English, and had intact sensory and motor skills. The current study was approved by the Institutional Review Board (Indiana University IRB \#1202008012).

While home-schooled, AR had been receiving individual speechlanguage therapy service from a university clinic since 2010 to work on his speech-language problems including articulation, phonological awareness, and spelling. Over 2 years of services, most of his articulation deficits resolved except for sound clusters including $/ r /$, but he continued to struggle with reading and writing, especially when spelling words likely to be acquired through reading versus oral communication (e.g., island). Before participating in this research project, he reported that he felt goals focused on spelling were the most beneficial and important to him compared to his other speech-language therapy goals and tasks. Therefore he was introduced to and participated in this research project.

CR visited and then was evaluated in the university clinic at the age of 35 due to his reading concerns. He had never received any prior speech-language intervention services despite experiencing reading and writing difficulties all of his life. He reported difficulties with decoding and spelling, especially of irregularly spelled words, and that he had struggled with this issue throughout his educational career. He expressed concern that his frequent spelling errors were affecting his work performance because his current job required writing many reports and emails, often entailing detailed explanations. He noticed that he frequently substituted incorrect words that shared some spelling overlap with the target words (e.g., it for in, tenth for tense). He also reported that he often misread sight words including store signs and advertisements when driving. He described himself as a 'slow reader' and 'bad speller' and recently pursued training opportunities for these symptoms.

\section{Pre- and Post-assessment Procedures}

Although both participants showed similar written language symptoms (i.e., slow and effortful reading and writing), their cognitive and linguistic strengths and weaknesses varied. Thus, cognitive and language testing was administered before treatment to the participants to establish their baseline performance. To measure cognitive skills, the following tests were given: (1) the Wechsler Memory Scale-III (WMS-III; Wechsler, 1997) to assess verbal and nonverbal memory; (2) the Test of Everyday Attention (TEA; Robertson et al., 1994) for CR and TEA-Children (TEA-ch; Manly, Robertson, Anderson, \& Nimmo-Smith, 1999) for AR to test sustained, selective, and divided attention skills; (3) the Design Fluency subtests of Delis-Kaplan Executive Function System (D-KEFS; Delis, Kaplan, \& Kramer, 2001) to measure executive function; and, (4) the picture version of Pyramids and Palm trees (PPT; Howard \& Patterson, 1992) to test semantic knowledge and processing.

To assess language skills, we administered: (1) the Clinical Evaluation of Language Fundamentals-4 (CELF-4; Semel, Wiig, \& Secord, 2003) to determine participants' level of morphological, syntactic, semantic, pragmatic, and phonological awareness processing; (2) Comprehensive Test of Phonological Processing-2 (CTOPP-2; Wagner, Torgesen, Rashotte, \& Pearson, 2013) for AR, and CTOPP-2 (Wagner et al., 2013) for CR for an in-depth examination of phonological processing skills; and (3) Grey Oral Reading Test-4 (GORT4; Wiederholt \& Bryant, 2001) to measure oral reading skills for CR. Two types of written discourse samples (narrative and procedural) were obtained for each participant to determine the number of words produced in their writing samples and to examine informativeness using correct information unit analysis (Nicholas \& Brookshire, 1993), a reliable and commonly used measure that quantifies the extent to which discourse samples are accurate, relevant, and informative. Narrative discourse samples were elicited by asking participants to write down the story depicted in "The Bear and the Fly" (Winter, 1976), a picture booklet without words, and procedural discourse samples were elicited by asking participants to write down how to make a peanut butter and jelly sandwich.

In addition, $\mathrm{AR}$ was given the Test of Language CompetenceExpanded Edition to assess his metalinguistic skills, including comprehension of ambiguous sentences and figurative language, and making inferences. Some test results were retrieved from the 
participants' most recent clinic evaluation reports, all of which had been administered between one to nine months before treatment; such test data included the following: (1) Test of Memory and Learning-2 (TOMAL-2; Reynolds \& Voress, 2007) to measure verbal, nonverbal, and delayed memory and learning skills for AR, (2) the Qualitative Reading Inventory-5 (QRI-5; Leslie \& Caldwell, 1995) for AR, as an informal assessment of reading and comprehension skills for narrative and expository passages, and (3) the Detroit Test of Learning Aptitude-4 (DTLA-4; Hammill, 1998) to examine short- and long-term memory and visual-motor integration for CR.

After the completion of treatment, some of the linguistic and cognitive assessment tools were selected and re-administered to determine transfer effects of treatment to those tests.

\section{Participants' Pre-treatment Profiles}

Participant AR

Pre-treatment testing revealed that AR had overall good memory skills (see Tables 1 and 2). He showed a relative strength in his WM skills, performing at the 88th percentile on the WMS-III WM index. However, this strength seemed domain-specific because his span task performances were consistently better on those tasks involving letter versus digit stimuli (i.e., he scored at the $75 \%$ ile for the letters backward span vs. 9\%ile for the digits backward span). On all the other WMS-III subtests and verbal memory subtests of the TOMAL-2, he scored near or above average (e.g., 70\%ile for the general memory domain of WMS-III).

With respect to phonological processing, he displayed poor phonological awareness, particularly on the CTOPP Elision (i.e., ability to remove a sound from a word to form a new word), scoring at the 1st percentile. This task not only requires processing phonological information, but also make demands upon the central executive component of WM (e.g., manipulating a sound to form new words). In contrast, tasks with primary demands on the phonological buffer component of WM were less challenging for ARe.g., scaled score of 8 (mean $=10, S D=3)$ on the CELF-4 Recalling Sentences and CTOPP Nonword Repetition subtests. Accordingly, AR's phonological processing performance appeared vulnerable when there was an increasing demand on the central executive component while processing phonological information.
Table 1. AR's language assessment results

\begin{tabular}{|c|c|c|}
\hline & Pre-treatment & Post-treatment \\
\hline \multicolumn{3}{|l|}{ CTOPP raw score (SS) } \\
\hline Elision & $7(3)$ & $8(4)$ \\
\hline Blending words & $11(7)$ & $12(7)$ \\
\hline Memory for digits & $15(10)$ & $12(7)$ \\
\hline Rapid digit naming (s) & $23(10)$ & $27.9(8)$ \\
\hline Nonword repetition & $12(8)$ & $12(8)$ \\
\hline Rapid letter naming (s) & $30(8)$ & $31.4(6)$ \\
\hline \multicolumn{3}{|l|}{ CTOPP composite score (SS) } \\
\hline Phonological awareness & $70(2)$ & $73(3)$ \\
\hline Phonological memory & $94(35)$ & $85(16)$ \\
\hline Rapid naming & $94(35)$ & $82(12)$ \\
\hline Alt. Phonological awareness & N/A & $79(13)$ \\
\hline \multicolumn{3}{|l|}{ CELF-4 raw score (SS) } \\
\hline Recalling sentences & $72(8)$ & - \\
\hline Formulated sentences & $35(2)$ & - \\
\hline Word classes & $20(10)$ & - \\
\hline Word definitions & $34(13)$ & - \\
\hline Core language standard score & 104 & - \\
\hline Core language percentile & 61 & - \\
\hline \multicolumn{3}{|l|}{ TLC-E raw score (SS) } \\
\hline Ambiguous sentences & $18(5)$ & - \\
\hline Listening comprehension: making inferences & $34(11)$ & - \\
\hline Figurative language & $14(4)$ & $25(7)$ \\
\hline \multicolumn{3}{|l|}{ GORT-4 (\%ile) } \\
\hline Oral reading quotient & - & $70(2)$ \\
\hline Fluency score & - & $59(<1)$ \\
\hline Comprehension score & - & $48(25)$ \\
\hline \multicolumn{3}{|l|}{ QRI-5 (oral reading) } \\
\hline Correct words per minute & 73.8 & 96.9 \\
\hline \multicolumn{3}{|l|}{ Narrative discourse sample } \\
\hline Number of total words & 55 & 96 \\
\hline Number of CIUs & 50 & 82 \\
\hline $\operatorname{CIU}(\%)$ & 90.9 & 85.42 \\
\hline \multicolumn{3}{|l|}{ Procedural discourse sample } \\
\hline Number of total words & 35 & 50 \\
\hline Number of CIUs & 32 & 38 \\
\hline $\operatorname{CIU}(\%)$ & 91.42 & 76 \\
\hline
\end{tabular}

CTOPP $=$ Comprehensive Test of Phonological Processing; CELF-4=Clinical Evaluation of Language Fundamentals-4; TLC-E-Test of Language Competence-Expanded; GORT-4 = Grey Oral Reading Test-4; QRI = Qualitative Reading Inventory-5; CIU= correct information units; $S S=$ scaled score $(M=10, S D=3)$.

AR exhibited generally good language performance except for one CELF-4 subtest, Formulated Sentences. This subtest is very complicated compared to other CELF-4 subtests in that it requires when given an orally-presented target word, in reference to a visual stimulus: (1) using the given word, (2) generating a sentence that 
Eun Jin Paek, et al. • A Novel Cognitive-Linguistic Approach to Addressing Developmental Reading Disorders

Table 2. AR's cognitive assessment results

\begin{tabular}{|c|c|}
\hline & Pre-treatment \\
\hline \multicolumn{2}{|l|}{ TOMAL-2 raw score (\%ile) } \\
\hline \multicolumn{2}{|l|}{ Verbal memory } \\
\hline Memory for stories & $35(75)$ \\
\hline Word selective reminding & 72 (95) \\
\hline Object recall & $54(25)$ \\
\hline Paired recall & $28(63)$ \\
\hline \multicolumn{2}{|l|}{ Attention/concentration } \\
\hline Digits forward & $48(37)$ \\
\hline Letters forward & $47(63)$ \\
\hline Digits backward & $11(9)$ \\
\hline Letters backward & $36(75)$ \\
\hline \multicolumn{2}{|l|}{ WMS-III sum of SS (\%ile) } \\
\hline Auditory immediate & $20(47)$ \\
\hline Visual immediate & $21(58)$ \\
\hline Immediate memory & $41(55)$ \\
\hline Auditory delayed & $23(70)$ \\
\hline Visual delayed & $20(50)$ \\
\hline Auditory recognition delayed & $13(84)$ \\
\hline General memory & $56(70)$ \\
\hline Working memory & $26(88)$ \\
\hline \multicolumn{2}{|l|}{ TEA-ch raw score (SS) } \\
\hline \multicolumn{2}{|l|}{ Sky search } \\
\hline Number of correctly identified & $19(10)$ \\
\hline Time per target & 15 \\
\hline Score! & $10(11)$ \\
\hline Sky search DT & $1.6(6)$ \\
\hline Map mission & $59(11)$ \\
\hline Score DT & $20(13)$ \\
\hline \multicolumn{2}{|c|}{ D-KEFS design fluency test raw score (SS) } \\
\hline Filled & $12(12)$ \\
\hline Empty & $14(12)$ \\
\hline Switching & $13(15)$ \\
\hline Sum of SS (composite SS) & $39(14)$ \\
\hline \multicolumn{2}{|c|}{ Pyramids and Palm Trees raw score (\%) } \\
\hline Picture version & $48(92)$ \\
\hline
\end{tabular}

TOMAL-2 = Test of Memory and Learning-2; WMS-III = Wechsler Memory Scale-III; TEA-ch= Test of Everyday Attention-children; D-KEFS= Delis-Kaplan Executive Function System; CIU = correct information units; $S S=$ scaled score $(M=10, S D=3)$.

corresponds to the picture, and also the sentence should be (3) grammatically correct, and (4) complete. His scaled score for this subtest was only $2($ mean $=10, S D=3)$, in striking contrast to his overall core language skills, which placed him at the 61st percentile. Supporting this weakness on more complicated tasks, among the attention subtests, he displayed the most difficulty on the divided attention subtest (i.e., Sky Search DT of TEA-ch), which demands attention to and processing of multiple tasks at the same time. In light of these strengths and weaknesses and prior research (e.g., Dahlin, 2011), it was conjectured that a complex WM intervention with phonologically challenging stimuli would yield benefits to his reading skills.

\section{Participant CR}

For CR (see Table 3), phonological memory was a primary area of weakness (i.e., 5\%ile on both the DTLA-4 Sentence Imitation and CTOPP-2 Nonword Repetition subtests). His phonological awareness skills fell at the low end of the normal range (SS=7, 16\%ile), when assessed by the CTOPP-2 Elision and Phoneme Isolation subtest. He also exhibited deficits in visual working memory (2\%ile on the TOMAL-2 Memory for Location) and sustained attention (scaled score $=5$ on TEA Map Search 2). We assumed that this below average performance of sustained attention and working memory subtests might have, at least in part, contributed to his poor reading (GORT-4 Fluency < 1\%ile), given the influential relationship between reading ability and the phonological store (e.g., Menghini, Finzi, Carlesimo, \& Vicari, 2011).

\section{Study Design and Probe Tasks}

This study involved a multiple baseline single case experimental design (Tate et al., 2014). Participant AR was the first person to receive treatment, and participant CR was the second person who participated in the study after the intervention was completed for AR. A staggered baseline across participants, however, could not be implemented because CR could not visit the study site (i.e., the university clinic), which was located in a different city from his home, for more than three baseline sessions due to the cost and difficulties of long distance travel. To measure cognitive-linguistic changes over the course of the experiment, three different types of WM tasks served as probe tasks: N-back, Reconstitution of Words, and Reading Span tasks (see Table 4 for a description of each task; for an in depth review of these tasks; see also Conway et al., 2005). These tasks were selected given their established validity as WM measures (e.g., Jaeggi, Buschkuehl, Perrig, \& Meier, 2010; Vallat et al., 2005; Wright \& Fergadiotis, 2012). The Reconstitution of Words task (Vallat et al., 2005) represented a more basic WM task, during which minimal to modest manipulation or processing (i.e., phonological and lexical processing) of information is required while 
Table 3. CR's language and cognitive assessment results

\begin{tabular}{|c|c|c|c|c|}
\hline & Pre-treatment & Post-treatment & Follow-up & $\mathrm{RCls}$ \\
\hline \multicolumn{5}{|l|}{ CTOPP-2 raw score (SS) } \\
\hline Elision & $24(7)$ & $30(10)^{*}$ & $30(10)^{*}$ & $2.12,2.12$ \\
\hline Blending words & $27(11)$ & $31(15)^{* * *}$ & $28(12)$ & $2.82, \mathrm{NS}$ \\
\hline Memory for digits & $16(7)$ & $15(6)$ & $18(7)$ & NS, NS \\
\hline Rapid digit naming (s) & $13.63(9)$ & $14(8)$ & $12(10)$ & - \\
\hline Nonword repetition & $13(5)$ & $16(6)$ & $16(6)$ & NS, NS \\
\hline Rapid letter naming (s) & $14.21(8)$ & $13(9)$ & $12(10)$ & - \\
\hline Phoneme isolation & $23(7)$ & $26(9)$ & $26(9)$ & NS, NS \\
\hline Segmenting nonwords & $22(10)$ & $23(10)$ & $23(10)$ & NS, NS \\
\hline \multicolumn{5}{|l|}{ CTOPP-2 composite score (SS) } \\
\hline Phonological awareness & $90(25)$ & $110(75)^{* * *}$ & $103(58)^{* * *}$ & $3.54,2.30$ \\
\hline Phonological memory & $76(5)$ & $76(5)$ & $79(8)$ & NS, NS \\
\hline Rapid naming & $92(30)$ & $92(30)$ & $101(53)$ & - \\
\hline Alt. Phonological awareness & $92(30)$ & $104(61)^{*}$ & $98(45)$ & 2.12, NS \\
\hline \multicolumn{5}{|l|}{ CELF-4 raw score (SS) } \\
\hline Recalling sentences & $84(10)$ & - & - & - \\
\hline Formulated sentences & $50(10)$ & - & - & - \\
\hline Word classes & $40(19)$ & - & - & - \\
\hline Word definitions & $41(14)$ & - & - & - \\
\hline Core language standard score & 120 & - & - & - \\
\hline Core language percentile & $91 \%$ ile & - & - & - \\
\hline \multicolumn{5}{|l|}{ GORT-4 (\%ile) } \\
\hline Form & A & B & $A$ & - \\
\hline Oral reading quotient & $67(1)$ & 94 (34) & 94 (34) & - \\
\hline Fluency score & $55(<1)$ & $89(16)^{* * *}$ & $89(16)^{* * *}$ & $4.24,4.24$ \\
\hline Comprehension score & $50(25)$ & $65(63)^{*}$ & $62(63)^{*}$ & $2.12,2.12$ \\
\hline \multicolumn{5}{|l|}{ QRI-5 (oral reading) } \\
\hline Correct words per minute & 92 & $\mathrm{~N} / \mathrm{A}$ & N/A & N/A \\
\hline \multicolumn{5}{|l|}{ Narrative discourse sample } \\
\hline Number of total words & 243 & 234 & - & - \\
\hline Number of CIUs & 230 & 223 & - & - \\
\hline CIU (\%) & 94.65 & 95.29 & - & - \\
\hline \multicolumn{5}{|l|}{ Procedural discourse sample } \\
\hline Number of total words & 144 & 190 & - & - \\
\hline Number of ClUs & 142 & 185 & - & - \\
\hline CIU (\%) & 98.61 & 97.36 & - & - \\
\hline \multicolumn{5}{|l|}{ DTLA-4 raw score (\%ile) } \\
\hline Word opposites & $45(84)$ & - & - & - \\
\hline Design sequences & $129(37)$ & - & - & - \\
\hline Sentence imitation & $14(5)$ & $19(25)^{* * *}$ & $19(25)^{* * *}$ & $3.54,3.54$ \\
\hline Reversed letters & $36(37)$ & $40(50)^{* * *}$ & $43(63)^{* * *}$ & $2.82,4.95$ \\
\hline Story construction & $27(84)$ & - & - & - \\
\hline Design reproduction & 39 (37) & - & - & - \\
\hline Basic information & $36(95)$ & - & - & - \\
\hline Symbolic relations & $24(50)$ & - & - & - \\
\hline Word sequences & $14(25)$ & $10(9)$ & $12(16)$ & NS, NS \\
\hline Story sequences & $43(75)$ & - & - & - \\
\hline
\end{tabular}


Eun Jin Paek, et al. • A Novel Cognitive-Linguistic Approach to Addressing Developmental Reading Disordek COMmuniCATION SCIENCES\& DISORDERS

Table 3. Continued

\begin{tabular}{|c|c|c|c|c|}
\hline & Pre-treatment & Post-treatment & Follow-up & $\mathrm{RCls}$ \\
\hline \multicolumn{5}{|l|}{ TOMAL-2 raw score (\%ile) } \\
\hline Verbal memory & - & - & - & - \\
\hline Memory for stories & $36(84)$ & - & - & - \\
\hline Word selective reminding & $60(50)$ & - & - & - \\
\hline Object recall & $65(75)$ & - & - & - \\
\hline Paired recall & $29(75)$ & - & - & - \\
\hline Nonverbal memory & - & - & - & - \\
\hline Facial memory & $32(50)$ & - & - & - \\
\hline Abstract visual memory & $35(63)$ & - & - & - \\
\hline Visual sequential memory & $27(37)$ & - & - & - \\
\hline Memory for location & $4(2)$ & - & - & - \\
\hline \multicolumn{5}{|l|}{ WMS-III sum of SS (\%ile) } \\
\hline Auditory immediate & $27(91)$ & - & - & - \\
\hline Visual immediate & $19(42)$ & - & - & - \\
\hline Immediate memory & $46(75)$ & - & - & - \\
\hline Auditory delayed & $25(82)$ & - & - & - \\
\hline Visual delayed & $23(73)$ & - & - & - \\
\hline Auditory recognition delayed & $12(75)$ & - & - & - \\
\hline General memory & $60(82)$ & - & - & - \\
\hline Working memory & $27(92)$ & - & - & - \\
\hline \multicolumn{5}{|l|}{ TEA raw score (SS) } \\
\hline Version & A & B & A & - \\
\hline Map search 1 & 37 (9) & $46(11)$ & $43(10)$ & - \\
\hline Map search 2 & $57(5)$ & $73(10)$ & $74(10)$ & - \\
\hline Elevator counting & 7 (normal) & 7 (normal) & 7 (normal) & - \\
\hline Elevator counting w/D & $8(9)$ & $10(13)$ & $6(7)$ & - \\
\hline Telephone search & $3.47(8)$ & $2.95(9)$ & $2.79(11)$ & - \\
\hline Telephone search w/D & - & - & - & - \\
\hline Dual task decrement & $2.55(8)$ & $.05(12)$ & $.26(12)$ & - \\
\hline \multicolumn{5}{|c|}{ D-KEFS design fluency test raw score (SS) } \\
\hline Filled & $7(8)$ & $10(10)$ & $12(12)$ & NS, NS \\
\hline Empty & $9(9)$ & $11(10)$ & $13(12)$ & NS, NS \\
\hline Switching & $6(8)$ & $9(11)$ & $9(11)$ & NS, NS \\
\hline Sum of SS (composite SS) & $25(8)$ & $30(10)$ & $35(12)$ & - \\
\hline \multicolumn{5}{|c|}{ Pyramids and Palm Trees raw score (\%) } \\
\hline Picture version & $51(98)$ & - & - & - \\
\hline
\end{tabular}

$\mathrm{RCl}=$ reliable change indices; CTOPP-2 = Comprehensive Test of Phonological Processing-2; CELF-4=Clinical Evaluation of Language Fundamentals-4; GORT-4=Grey Oral Reading Test-4; QRI= Qualitative Reading Inventory-5; CIU = correct information units; DTLA=Detroit Test of Learning Aptitude-4; TOMAL-2=Test of Memory and Learning-2; WMS-III= Wechsler Memory Scale-III; TEA= Test of Everyday Attention; D-KEFS=Delis-Kaplan Executive Function System; $S S=$ scaled score $(M=10, S D=3) ; N S=$ not significant.

RCls are calculated based on the score differences between 'pre-treatment and post-treatment' and 'pre-treatment and 6-week follow-up'. Scaled scores and percentile values of CTOPP-2, GORT-4, and DTLA-4 were determined using the oldest normative data available from each technical manual. ${ }^{*} p<.05,{ }^{* *} p<.01,{ }^{* * *} p<.005$.

the participants try to remember the presented stimuli (i.e., letters) and concomitantly reconstitute the word that the letters spell. In the N-back task, a commonly utilized WM task (Conway et al., 2005; Mayer \& Murray, 2012), a series of stimuli is presented con- tinuously and participants try to constantly update and manipulate information while selecting and inhibiting responses. Thus, this task requires continuous updating of the mental representations of the target stimuli, and also demands central executive pro- 
Table 4. Treatment activities

\begin{tabular}{|c|c|c|}
\hline Task & Description & Example stimulus and expected participant response \\
\hline $\begin{array}{l}\text { Reading span (Adapted } \\
\text { from Mayer \& } \\
\text { Murray, 2002) }\end{array}$ & $\begin{array}{l}\text { The participant judges the grammaticality of two sentences one by one, while re- } \\
\text { membering the last word of each sentence. He then must decide whether those } \\
\text { last two words rhyme or not, and generate a third rhyming word. The number of } \\
\text { sentences per set increases from two to four, and four to six and the length of each } \\
\text { sentence increases from six to eight as his performance improves. }\end{array}$ & $\begin{array}{l}\text { Stimulus: } \\
\text { (a) Stop before another word is spoken. (correct) } \\
\text { (b) Unfortunately Jane's new vase are broken. (incorrect) } \\
\text { Expected participant response: correct, incorrect, yes they } \\
\text { rhyme, token. }\end{array}$ \\
\hline $\begin{array}{l}\text { N-back (Adapted from } \\
\text { Cicerone, 2002) }\end{array}$ & $\begin{array}{l}\text { The participant states 'yes' if the current stimulus item that he is seeing is the same } \\
\text { as the stimulus item that he saw N-back ago. The participant begins with a 1-back } \\
\text { task and moves onto 2- and 3-back tasks as he shows improvement on this task. }\end{array}$ & $\begin{array}{l}\text { Stimulus (2-back task): boost moose mouse moose* boast } \\
\text { mouse boost ...... } \\
\text { Expected participant response: "yes" to words with an as- } \\
\text { terisk. }\end{array}$ \\
\hline $\begin{array}{l}\text { Updating (Adapted from } \\
\text { Morris \& Jones, } \\
\text { 1990) }\end{array}$ & $\begin{array}{l}\text { A string of words is visually presented and the participant must recall the last four } \\
\text { items after the presentation is unexpectedly stopped. He is also asked to write } \\
\text { down the words that he had to remember. }\end{array}$ & $\begin{array}{l}\text { Stimulus: Acquire, sense, which, until, acquit, dumbbell, } \\
\text { weird, exceed, sergeant } \\
\text { Expected participant response: dumbbell, weird, exceed, } \\
\text { sergeant (both in spoken and written modality). }\end{array}$ \\
\hline $\begin{array}{l}\text { Reconstruction of } \\
\text { words (Adapted from } \\
\text { Vallat et al., 2005) }\end{array}$ & $\begin{array}{l}\text { The participant must reconstruct and say an irregular word that was spelled out by } \\
\text { the clinician. The length of trained words is increased from 3- to 6-letters. }\end{array}$ & $\begin{array}{l}\text { Stimulus: } 0, n, c, e \\
\text { Expected participant response: once }\end{array}$ \\
\hline $\begin{array}{l}\text { Odd-One out (Adapted } \\
\text { from Russell et al., } \\
\text { 1996) }\end{array}$ & $\begin{array}{l}\text { The participant looks at three words presented in squares in a line (i.e., left, middle, } \\
\text { and right), and picks one that doesn't share the same initial string of letters with the } \\
\text { other two. The procedure is repeated with another set of items and then the partici- } \\
\text { pant must recall the positions of the odd-one-out words (e.g., "left"' and "middle") }\end{array}$ & $\begin{array}{l}\text { Stimulus: receipt recommend precede until annex anthill } \\
\text { Expected participant response: } \\
\text { First trial: "precede" } \\
\text { Second trial: "until" } \\
\text { Location: right and left }\end{array}$ \\
\hline $\begin{array}{l}\text { Keep track (Adapted } \\
\text { from Yntema, 1963) }\end{array}$ & $\begin{array}{l}\text { Three categories with specific letter strings are placed at the bottom of a computer } \\
\text { monitor and a string of words is presented one by one. The participant must update } \\
\text { these words into an appropriate category and then recall the most recent word in } \\
\text { each of the categories after presentation. }\end{array}$ & $\begin{array}{l}\text { Stimulus: Category example: sc-, tr-, al- } \\
\text { Word string: school, ally, try, tree, scramble, scar, allure } \\
\text { Expected participant response: Tree, scar, allure }\end{array}$ \\
\hline
\end{tabular}

cesses to strategically ignore or drop irrelevant stimuli. Lastly, a Reading Span task was utilized as a more complex WM task, during which participants perform basic types of WM tasks (i.e., remembering the final words of multiple sentences presented one by one) while also performing another task (i.e., judging grammaticality of each sentence) during or between the presentation of target words to be stored in their memory (Conway et al., 2005; Mayer \& Murray, 2002).

These three probe tasks were administered before, during, and after treatment as well as at the 6-week follow-up. Before treatment, $\mathrm{AR}$ and $\mathrm{CR}$ were tested three times to establish their baseline performance. Each probe task had two sets of stimuli: one set (i.e., probe set) was used for probing throughout all phases of the study, whereas the other set (i.e., exposure set) served as an untrained set to control for exposure effects, and was only used during baseline, posttreatment, and the 6-week follow-up probing. All target words for the probe tasks had spellings with a low probability of phonemeto-grapheme conversion and were selected from the Johns Hopkins Dysgraphia Battery (Goodman \& Caramazza, 1985) or Words Their Way (Bear, Invernizzi, Templeton, \& Johnston, 2012), a workbook for school-aged children and adolescents that includes myriads of irregular word stimuli based on different stages of spelling skills. Psycholinguistic variables including word frequency, number of syllables, and number of letters were balanced across the exposure and probe sets to assure a similar level of difficulty.

As an outcome measure for the N-back task, a signal detection statistic was used to calculate the probability of correctly selecting a target (Mayer \& Murray, 2012). This was calculated by subtracting the false alarm rate (i.e., the number of items to which the participant said 'yes' while the actual answer was 'no') from the correct hit rate (i.e., the number of items to which the participant said 'yes' correctly). For the other two probe tasks, the accuracy for the WM component as well as the written verbal responses were recorded to examine the effect of the intervention on both WM and phonological processing, respectively.

\section{Treatment Procedures}

During the treatment phase, AR was individually provided with weekly 90-minute treatments for 14 weeks. CR received individual sessions for 20 weeks; he received more treatment sessions than 
Eun Jin Paek, et al. • A Novel Cognitive-Linguistic Approach to Addressing Developmental Reading Disordeke

AR because AR did not want to attend treatment during school breaks. For both participants, training consisted of practicing six verbal WM tasks (N-back, Reconstitution of Words from Oral Spelling, Reading Span, Odd-One Out, Updating, and Keep Track), all of which were adapted from WM interventions that in previous literature evoked improvements in cognitive-linguistic abilities, albeit in different patient populations (for a description of each task) (Table 4). All tasks were developed to tap the central executive as well as phonological store components of WM (Baddeley, 2003) and core reading skills. In each session, three to four different activities were practiced to promote maintained interest within and across treatment sessions. Each treatment task was practiced between four to ten times throughout the treatment phase of the study, with treatment activities pseudo-randomly selected and ordered within and across each session to minimize order effects.

Treatment activities became increasingly difficult as participants' performance improved at each level. That is, if a participant achieved over $80 \%$ accuracy across two consecutive sessions on a task, the next most difficult level of that treatment task was introduced. This individualized adaptive training approach was selected to allow individuals to make optimal use of their latent potential (Morrison \& Chein, 2011). The level of task difficulty was raised by increasing either the number of stimuli in each trial (e.g., Updating task) or the length of the stimuli (i.e., more letters in a word or more words in a sentence; e.g., Reconstitution of Words, and Reading Span task). Each training task at each difficulty level consisted of multiple stimulus sets: Tasks that included relatively more or longer stimuli and thus required a longer time to complete (i.e., Reading Span, N-back, and Reconstitution of words) had two stimulus sets, whereas tasks with a relatively shorter administration time (i.e., Odd-One Out, Updating, and Keep Track) had four stimulus sets.

In addition to these direct cognitive-linguistic stimulation tasks, participants were provided with compensatory strategy training. The strategies introduced and encouraged during treatment activities included visualization (visual imagery), verbal rehearsal, chunking, and a combination of these, namely a dual coding strategy (Morrison \& Chien, 2011; Murray, 2012). Before the beginning of each treatment task, the clinician and participant discussed how practicing the task would lead to benefits in the participant's daily life (e.g., talk about to what everyday situation the task might be rele- vant, such as for the Reconstitution of Words from Oral Spelling task, writing down a name with an irregular spelling or remembering restaurant names that have irregular spellings). The clinician also discussed the participant's prior performance level and the level of difficulty for each task, so that the participant could better prepare for the next task trial and generate and select the strategies he thought would support his task performance. Throughout training, participants were given feedback about their performance. For example, if a participant responded correctly, the clinician let him know that his response was correct and provided positive verbal reinforcement (e.g., "Great, you got it correct."). If a participant responded incorrectly, the clinician told the participant about the inaccurate response and asked him to repeat the trial again, encouraging incorporation and utilization of strategies germane to the task as needed.

Treatment stimuli for each participant were determined based on his current spelling and reading abilities and personal interests and differed from those in the probe tasks. Some stimuli came from the spelling inventory of Words Their Way (Bear et al., 2012) and represented examples of each written language developmental stage. For example, AR was below the 'Within Word Pattern Sort' stage in his spelling skills based on the inventory guide, so his treatment stimuli included some words in the 'r-Blends' (e.g., grin, or girl), a category of the Within Word Pattern Sort stage. For CR, irregular words with low phoneme-to-grapheme conversion probability were identified that would be functionally relevant to his occupation and daily life (e.g., analysis, daiquiri). Treatment stimuli also included some functional items for each participant to foster their motivation during treatment sessions. For example, AR and his mother generated a list that included more than hundred words, which were of interest to AR (e.g., sports terms like steal and dribble).

Graduate-level student speech-language clinicians provided the intervention to the participants (i.e., each participant received treatment from a different student clinician). Accordingly, intervention scripts were developed that included instructions and possible cues and feedback for each task. A treatment fidelity rubric with nine different components was created to ensure the application of consistent treatment procedures across sessions and clinicians (Table 5). The accuracy of clinician instruction and feedback was calculated component-by-component to determine treatment fi- 
Table 5. Fidelity rubric

\begin{tabular}{ll}
\hline When & \multicolumn{1}{c}{ Components } \\
\hline Before the task trial & Introduce the task (name it and remind the participant about what it is). \\
& Discuss how working on this task helps the participant. \\
& Brainstorm, remind, and/or discuss strategies for the task. \\
& (When applicable) Review scores from last session and plan to achieve better. \\
During the task trial & $\begin{array}{l}\text { Administer tasks with appropriate stimuli at an appropriate rate. } \\
\text { Provide positive reinforcement. }\end{array}$ \\
After the task trial & (When applicable) Feedback about incorrect performance and cues. \\
& Review the participant's performance (perceived difficulty and accuracy). \\
& Discuss how the participant's performance can be improved next time. \\
\hline
\end{tabular}

delity. Three sessions for each participant (i.e., approximately $15 \%$ of the total number of treatment sessions) were randomly chosen to calculate fidelity. For AR and CR, fidelity was found acceptable at $96.3 \%$ and $88.9 \%$, respectively.

\section{Data Analyses}

Probe tasks

Probe tasks performances were analyzed via visual data inspection suited for single subject analysis (Byiers, Reichle, \& Symons, 2012) and plotting of Shewhart-chart trend lines (Robey, Schultz, Crawford, \& Sinner, 1999; Shewhart, 1931). The horizontal Shewhart-chart trend line indicates meaningful changes over time relative to baseline performance, using standard deviations and pretreatment mean test scores. Given our interest in treatment effects in the positive direction, only the upper line was drawn for each probe set, with two successive data points over this line indicating significant improvement during the treatment phase (Robey et al., 1999). Thus, the total number of probe data points as well as the number of consecutive data points over the line were counted. Tau$U$ statistics (Parker, Vannest, Davis, \& Sauber, 2011) were also calculated to determine the presence of a treatment effect. Tau- $U$ provides a reliable and complete statistical analysis for single-case research as it controls the undesirable positive trend in the pre-treatment phase. Given our experimental design of $\mathrm{A}_{1} \mathrm{BA}_{2} \mathrm{~A}_{3}$, we also calculated Busk and Serlin's $d$ statistics $\left(d_{1}\right)$, which is one of the most reliable estimators for quantifying the effect size in behavioral language treatment studies (Beeson \& Robey, 2006). A priori set values were used to interpret the magnitude of effect sizes (i.e., small $<1.5$, medium $>1.5$ and $<3$, large $>3$ ) based on previous cognitive treatment research (Dahlin et al., 2009; Mayer \& Murrey, 2012).

\section{Cognitive-linguistic assessments}

To detect significant changes in performances on the standardized cognitive-linguistic assessments, reliable change indices (RCI; Jacobson \& Truax, 1991) were calculated and interpreted using standard error of measurement and the score difference between pre- and post-treatment and follow-up scores. As recommended by Jacobson and Truax (1991), RCI values over 1.96 were considered as statistically significant; that is, an RCI larger than 1.96 indicates that it is not likely to occur without true changes in test scores at two different time points.

\section{Written discourse sample analysis}

The total number of words produced and informativeness of the discourse samples were analyzed, calculating the proportion of correct information units (CIU) to quantify informativeness (Nicholas \& Brookshire, 1993). The first author analyzed all discourse samples in terms of CIU, and $20 \%$ of the samples were given to and analyzed by an undergraduate student majoring in Speech and Hearing Sciences, who was trained for the CIU analysis. Point-topoint inter-rater agreement for CIUs was determined and found acceptable at 93.1\%. Any disagreements were resolved through discussion. Point-to-point intra-rater agreement for CIUs was also examined for $20 \%$ of the samples and was $99.73 \%$.

\section{Subjective rating for functional changes}

Because CR himself was very concerned about his reading and writing in his daily life and work environment, we provided him with a subjective rating scale three times (i.e., before, during, and after treatment) to probe functional changes in some aspects of reading and writing. The Writer's Self Perception Scale and Reader's Self Perception Scale (Henk, Marinak, \& Melnick, 2012) were 
Eun Jin Paek, et al. • A Novel Cognitive-Linguistic Approach to Addressing Developmental Reading Disordeke

adopted, with some questions modified from the original version in terms of vocabulary to fit in our participant's situation (e.g., "Other students think I'm a good reader." was adapted for CR to "My colleagues or friends think I'm a good reader"). Both scales include four different subscales (Progress, Observational Comparison, Social Feedback, and Physiological States) to determine perceived changes in different domains. To score both scales, we followed the scoring rule provided by the original authors (i.e., strongly agree $=5$, agree $=4$, undecided $=3$, disagree $=2$, strongly disagree $=1$ for each item).

\section{RESULTS}

\section{Treatment Tasks}

Both participants showed improved performance on the six verbal WM treatment tasks. They both reached the criterion level (i.e., $80 \%$ response accuracy across two consecutive sessions) for the Reading Span and Odd-One Out treatment tasks, moving to at least the second level of difficulty for each of these tasks. In the other tasks, they demonstrated variable patterns of achievement, but both participants displayed improved scores on every task by the end of the treatment phase compared to the beginning

\section{Probe Task and Other Cognitive-Linguistic Outcomes}

Treatment outcomes are presented below for each participant in terms of: (1) probe outcomes via Tau- $U$ statistics, effect sizes, and maintenance of these probe gains, and (2) transfer effects and functional benefits. Given the number of figures that would be necessary to graphically display the probe outcomes for each participant, the probe data are instead summarized in table form only (Table 6).

\section{Participant AR}

Probe outcomes, effect size, and maintenance

For the probe set of stimuli (i.e., stimuli regularly probed throughout all phases of the study), AR showed statistically significant improvements on all outcome measures of the Reconstitution of Words (Tau- $U=.94, p=.03$ for reconstitution accuracy; Tau- $U=2.32$, $p=.02$ for written recall accuracy) (Tables 6-8) and N-back (Tau$U=.90, p=.03)$ probe tasks. Immediately following treatment termination, this improvement was also seen in the exposure set of stimuli (i.e., those only probed at pre-treatment, post-treatment, and follow-up) for both Reconstitution of Words measures. At the 6-week follow-up session, these significant gains on both the probe and exposure sets were maintained for Reconstitution of Words. Despite no generalization to the $\mathrm{N}$-back exposure set directly following treatment, AR did display significant improvement on this set at follow-up. The effect sizes ranged from medium (i.e., reconstitution accuracy on the Reconstitution of Words) to large (i.e., Nback, written recall from the Reconstitution of Words) for the probe tasks on which AR significantly improved (Table 7). In contrast, AR exhibited an increasing baseline trend on the rhyme judgment component of the Reading Span probe, with Tau- $U$ statistics (which

Table 6. Probe results presented in terms of percent accuracy

\begin{tabular}{|c|c|c|c|c|c|c|}
\hline \multirow{2}{*}{ Task } & & \multicolumn{2}{|c|}{ Pre-treatment } & \multirow{2}{*}{$\begin{array}{c}\text { During treatment } \\
\text { Exposure }\end{array}$} & \multirow{2}{*}{$\begin{array}{c}\text { Post-treatment } \\
\text { Exposure }\end{array}$} & \multirow{2}{*}{$\frac{\text { 6-week follow-up }}{\text { Exposure }}$} \\
\hline & & Mean \pm SD & Exposure & & & \\
\hline \multirow[t]{2}{*}{ N-back } & $A R$ & $51.35 \pm 6.66$ & $69.03 \pm 2.25$ & $73.5 \pm 12.42$ & $80(71.16)$ & $62.32(100)$ \\
\hline & CR & $48.93 \pm 12.27$ & $51.41 \pm 15.64$ & $85.57 \pm 5.73$ & 97.83 (88.99) & $88.99(60)$ \\
\hline \multirow{2}{*}{$\begin{array}{l}\text { Reconstitution of Words: } \\
\text { accuracy }\end{array}$} & $\mathrm{AR}$ & $28.33 \pm 12.58$ & $25 \pm 8.66$ & $53.57 \pm 9.35$ & $66(50)$ & $65(45)$ \\
\hline & CR & $46.67 \pm 15.28$ & $78.33 \pm 12.58$ & $84.5 \pm 6.43$ & $95(80)$ & $90(90)$ \\
\hline \multirow{2}{*}{$\begin{array}{l}\text { Reconstitution of Words: } \\
\text { written recall }\end{array}$} & $\mathrm{AR}$ & $25 \pm 5$ & $28.33 \pm 2.89$ & $49.17 \pm 7.36$ & $60(45)$ & $60(45)$ \\
\hline & CR & $33.33 \pm 11.54$ & $50 \pm 17.32$ & $65 \pm 10.27$ & $70(65)$ & $80(80)$ \\
\hline \multirow{2}{*}{$\begin{array}{l}\text { Reading Span: grammaticality } \\
\text { judgment }\end{array}$} & $\mathrm{AR}$ & $64.81 \pm 1.6$ & $54.62 \pm 8.9$ & $70.24 \pm 5.49$ & $69.44(61.11)$ & $66.67(61.11)$ \\
\hline & CR & $83.33 \pm 9.81$ & $88.63 \pm 11.54$ & $88.63 \pm 3.60$ & $94.44(94.44)$ & $88.89(97.22)$ \\
\hline \multirow[t]{2}{*}{ Reading Span: rhyme judgment } & $A R$ & $66.67 \pm 20.81$ & $70 \pm 17.32$ & $88.57 \pm 8.37$ & $80(70)$ & $70(70)$ \\
\hline & CR & $76.67 \pm 5.78$ & $76.67 \pm 23.09$ & $90 \pm 8.53$ & $90(90)$ & $90(100)$ \\
\hline \multirow{2}{*}{$\begin{array}{l}\text { Reading Span: generating } \\
\text { rhyming words }\end{array}$} & AR & $23.33 \pm 25.17$ & $16.67 \pm 5.78$ & $32.86 \pm 17.04$ & $50(10)$ & $50(10)$ \\
\hline & CR & $86.67 \pm 15.28$ & $73.33 \pm 28.87$ & $68.19 \pm 21.83$ & $80(60)$ & $80(70)$ \\
\hline
\end{tabular}

Exposure = untrained probe set to control for exposure effects, which was only used during baseline, post-treatment, and the 6-week follow-up probe assessments 
Table 7. Significance and magnitude of training effects

\begin{tabular}{|c|c|c|c|c|c|c|c|c|c|}
\hline \multirow{3}{*}{$\begin{array}{l}\text { N-back } \\
\text {-bol }\end{array}$} & \multirow[b]{3}{*}{$A R$} & \multicolumn{4}{|c|}{ Number of probe point over Shewhart-chart line } & \multicolumn{4}{|c|}{ Effect size (exposure) } \\
\hline & & \multirow{2}{*}{$\begin{array}{c}\begin{array}{c}\text { During treat- } \\
\text { ment }\end{array} \\
6\end{array}$} & \multirow{2}{*}{$\begin{array}{c}\begin{array}{c}\text { During treatment- } \\
\text { consecutive }\end{array} \\
6^{*}\end{array}$} & \multirow{2}{*}{$\begin{array}{c}\begin{array}{c}\text { Post-treatment } \\
\text { (exposure) }\end{array} \\
1(0)\end{array}$} & \multirow{2}{*}{$\begin{array}{c}\text { Follow-up } \\
\text { (exposure) }\end{array}$} & \multicolumn{2}{|c|}{ Pre vs. post } & \multicolumn{2}{|c|}{ Pre vs. follow-up } \\
\hline & & & & & & $12.75(.31)$ & Large & $4.88(4.64)$ & Large \\
\hline & $\mathrm{CR}$ & 11 & $11^{*}$ & $1(1)$ & $1(0)$ & $3.57(2.4)$ & Large & $2.9(.55)$ & Medium \\
\hline \multirow{2}{*}{$\begin{array}{l}\text { Reconstitution of Words: } \\
\text { accuracy }\end{array}$} & AR & 3 & $2^{*}$ & $1(1)$ & $1(1)$ & $2.99(2.89)$ & Medium & $2.91(2.3)$ & Medium \\
\hline & CR & 10 & $6^{*}$ & $1(\mathrm{~N} / \mathrm{A})$ & $1(\mathrm{~N} / \mathrm{A})$ & $3.62(.15)$ & Large & $3.23(.92)$ & Large \\
\hline \multirow{2}{*}{$\begin{array}{l}\text { Reconstitution of Words: } \\
\text { written recall }\end{array}$} & AR & 6 & $6^{*}$ & $1(1)$ & $1(1)$ & $7(5.77)$ & Large & $7(5.77)$ & Large \\
\hline & CR & 7 & $5^{*}$ & $1(0)$ & $1(0)$ & $3.17(.86)$ & Large & $4.04(1.73)$ & Large \\
\hline \multirow{2}{*}{$\begin{array}{l}\text { Reading Span: grammatical- } \\
\text { ity judgment }\end{array}$} & $A R$ & 4 & $4^{*}$ & $1(0)$ & $0(0)$ & $2.89(.73)$ & Medium & $1.16(.73)$ & Small \\
\hline & CR & $\mathrm{N} / \mathrm{A}$ & $\mathrm{N} / \mathrm{A}$ & $\mathrm{N} / \mathrm{A}$ & $\mathrm{N} / \mathrm{A}$ & $1.14(1.13)$ & Small & $0.59(1.38)$ & Small \\
\hline \multirow{2}{*}{$\begin{array}{l}\text { Reading Span: rhyme judg- } \\
\text { ment }\end{array}$} & AR & $\mathrm{N} / \mathrm{A}$ & $\mathrm{N} / \mathrm{A}$ & $\mathrm{N} / \mathrm{A}$ & $\mathrm{N} / \mathrm{A}$ & $3.84(4.04)$ & Large & $3.36(4.04)$ & Large \\
\hline & CR & 11 & $10^{*}$ & $1(\mathrm{~N} / \mathrm{A})$ & $1(\mathrm{~N} / \mathrm{A})$ & $0.23(.58)$ & Small & $0.23(1.01)$ & Small \\
\hline \multirow{2}{*}{$\begin{array}{l}\text { Reading Span: generating } \\
\text { rhyming words }\end{array}$} & $A R$ & 0 & 0 & $0(0)$ & $0(0)$ & $1.05(-1.15)$ & Small & $1.05(-1.15)$ & Small \\
\hline & CR & $\mathrm{N} / \mathrm{A}$ & $\mathrm{N} / \mathrm{A}$ & $\mathrm{N} / \mathrm{A}$ & $\mathrm{N} / \mathrm{A}$ & $2(.5)$ & Medium & $2(1)$ & Medium \\
\hline
\end{tabular}

Shewhart chart line analysis (Shewhart, 1931; Robey et al., 1999) and effect size measured by Busk and Serlin's $d$ statistics (Beeson \& Robey, 2006); interpretation of effect size was determined based on the effect size value for treatment probe sets.

Exposure $=$ untrained probe set to control for exposure effects, which was only used during baseline, post-treatment, and the 6-week follow up probe assessments; ${ }^{*}=$ more than two consecutive points observed over the Shewhart line, suggesting statistically significant treatment effects; N/A indicates that the Shewhart chart line could not be established because of increasing baseline trend or ceiling effects; '-' indicates that BR was not available for the post-treatment formal assessments and 6-week follow-up assessments.

take into consideration a rising baseline) indicating no treatment effect for this probe task (Tau- $U=.57, p=.17$ for grammaticality judgment; Tau- $U=.67, p=.11$ for rhyme judgment; Tau- $U=.19$, $p=.65$ for generating rhyming words).

\section{Transfer effects and functional benefits}

To detect any changes in his reading skills, especially in decoding, QRI-5 was administered again after the treatment phase. The number of correct words per minute AR read out loud substantially increased from 73.8 pre-treatment to 96.9 post-treatment (Tables 1 and 2). On the other cognitive-linguistic tests and discourse samples, there was nominal change. Although no formal test was administered to measure functional benefits for AR, his parent reported that this treatment program had resulted in improvements in AR's confidence, independence, and social interaction. His parent also reported that AR gained motivation to continue working on his reading skills through this treatment program.

\section{Participant CR}

Probe outcomes, effect size, and maintenance

Similar to his performance on some formal language subtests,
Table 8. Tau-U results for identifying treatment effects on the probe tasks

\begin{tabular}{lcccc}
\hline & & Tau-U & $Z$ & $p$-value \\
\hline N-back & AR & .90 & 2.17 & $.03^{*}$ \\
& CR & 1 & 2.57 & $.0102^{*}$ \\
Reconstitution of Words: accuracy & AR & .94 & 2.19 & $.0282^{*}$ \\
& CR & 1 & 2.54 & $.0112^{*}$ \\
Reconstitution of Words: written & AR & 1 & 2.32 & $.0201^{*}$ \\
recall & CR & 1 & 2.54 & $.0112^{*}$ \\
Reading Span: grammaticality & AR & .57 & 1.37 & .1715 \\
judgment & CR & .15 & .39 & .6971 \\
Reading Span: rhyme judgment & AR & .67 & 1.60 & .1106 \\
& CR & .80 & 2.09 & $.0364^{*}$ \\
Reading Span: generating rhyming & AR & .19 & .46 & .6485 \\
words & CR & -.48 & -1.25 & .2129 \\
\hline
\end{tabular}

${ }^{*} p<.05$.

$\mathrm{CR}$ displayed ceiling effects on the grammaticality judgment and generating rhyming words components of the Reading Span probe; thus Shewhart-chart lines could not be established for these outcome measures (Tables 6 and 7). Likewise, Tau- $U$ statistics indicated no change on these outcomes over time (Tau- $U=.15, p=.7$ for grammaticality judgment; Tau- $U=-.48, p=.21$ for generating rhyming words) (Table 8). Despite using a number of psycholinguistic properties to match the probe and exposure sets, during baseline, CR performed the Reconstitution of Words probe task 
Eun Jin Paek, et al. • A Novel Cognitive-Linguistic Approach to Addressing Developmental Reading Disorders

better in response to the exposure versus probe set of stimuli. This same response pattern was observed for the rhyme judgment component of the Reading Span probe. Therefore, Shewhart-chart lines could not be drawn for the reconstitution accuracy component of the Reconstitution of Words probe or the rhyme judgment component of the Reading Span probe.

CR's N-back performance did significantly improve over the course of treatment (Tau- $U=1, p=.01$ ), and this positive change was also identified in the probe set at the post-treatment and 6-week follow-up testing points; in contrast, a maintenance effect was not observed in the exposure set at the 6-week follow-up. CR also demonstrated significant improvements during the treatment and posttreatment phase on both components of the Reconstitution of Words probe (Tau- $U=1, p=.01$ for both reconstitution accuracy and written recall accuracy) and the rhyme judgment component of the Reading Span probe (Tau- $U=.80, p=.04$ ). These were maintained at the 6-week follow-up. When tested with the exposure set for the written recall component of the Reconstitution of Words probe, however, no gain was observed. The effect size measured for the $\mathrm{N}$-back probe was large at the post-treatment test and medium at the 6-week follow-up. For the Reconstitution of Words probe, a large treatment effect size was identified for both components at post-treatment as well as follow-up assessments. In contrast, only a small effect size was observed for the rhyme judgment component of the Reading Span task at the post-treatment and 6-week follow-up assessments.

\section{Transfer effects and functional benefits}

For CR, a more in-depth examination for the possible transfer effects was conducted using the CTOPP-2, GORT-4, TEA, Design Fluency test of D-KEFS, and some DTLA-4 subtests (Table 3). On the CTOPP-2, his overall phonological awareness abilities showed significant positive changes, as confirmed by the RCI analysis. A significant gain was also observed in the CTOPP-2 Alternative Phonological Awareness area. CR performed especially better on the Elision and Blending Words subtests of the CTOPP-2, both of which involve manipulating as well as storing phonemes of target words.

CR's oral reading quotient measured by the parallel forms of GORT-4 at post-treatment and follow-up sessions revealed significant gains (Table 3). For example, when compared to the norma-
Table 9. CR's perceived benefits as assessed by the WSPS and RSPS

\begin{tabular}{lrc}
\hline & Pre-treatment & Post-treatment \\
\hline WSPS subscale & & \\
General progress & 24 & 37 \\
Specific progress & 22 & 28 \\
Observational comparison & 23 & 29 \\
Social feedback & 15 & 26 \\
Physiological state & 14 & 24 \\
General statement & 2 & 4 \\
Total & 100 & 148 \\
RSPS subscale & & \\
Progress & 47 & 70 \\
Observational comparisons & 20 & 23 \\
Social feedback & 29 & 31 \\
Physiological state & 26 & 47 \\
General statement & 2 & 3 \\
Total & 124 & 182 \\
\hline
\end{tabular}

WSPS = Writer's Self Perception Scale; RSPS = Reader's Self Perception Scale (Henk, Marinak, \& Melnick, 2012).

tive data of the GORT-4's 18-year sample (the oldest sample group represented in the test manual), his scores moved from the $1 \%$ ile to the $34 \%$ ile following treatment. These substantial positive changes were observed not only in his fluency score but also his comprehension score.

CR's verbal WM and complex WM abilities, as measured by the DTLA-4 Sentence Imitation and Reversed Letters subtests, exhibited considerable improvement after the treatment, showing transfer effects. There were nominal positive changes in the other cognitive-linguistic measures of executive function and attention skills. His performance of one short-term verbal memory subtest (i.e., Word Sequences) significantly decreased directly following treatment, but by follow-up did not significantly differ from his pre-treatment performance. Importantly, CR reported perceived benefits of this treatment in his reading and writing (Table 9). His post-treatment responses on the self-rating scales exhibited considerable positive changes, particularly in the areas of progress and physiological state.

\section{CONCLUSION}

The purpose of this study was to examine the effects of a cognitive-linguistic treatment for developmental reading disorders. Two participants were trained with simple and complex verbal WM 
treatment tasks that involved word- and sentence-level stimuli with a low probability of phoneme to grapheme conversion and that were, at least in part, personally motivating for participants; the treatment also focused on strategy training. By probing individuals' responses over time, it was found that each participant made gains, although there was variation in the amount and pattern of improvement across participants. Direct replication of the improvement over the course of intervention across subjects, however, supported the generality of the treatment effect. Post-treatment evaluation outcomes indicated that this cognitive-linguistic intervention may indeed alleviate difficulties in reading as well as phonological processing. The clinical significance of our treatment approach was bolstered by participant-reported improvements and a parent's feedback, voluntarily submitted to the investigators.

Across the two participants, the strongest and most consistent evidence of treatment effects was observed on the Reconstitution of Words probe task. Compared to the other probe tasks (i.e., Reading Span and N-back), Reconstitution of Words required greater reliance on the phonological buffer but relatively less demand on the central executive component of WM; it might also be considered a more basic type of WM task as it does not add complex processing demands that should compete with the encoding processing (Daneman \& Carpenter, 1980).

With the current treatment protocol, not only near (improvements on WM tasks similar to trained tasks; Morrison \& Chein, 2011) but also far transfer effects (improvements on more disparate cognitive measures) were detected. For example, following treatment, AR displayed faster and more accurate text-level reading, and CR demonstrated various transfer effects ranging from improvement on phonological awareness and phonological memory tests to far transfer to oral reading and reading comprehension skills. WM training, by itself, has been previously found to facilitate reading comprehension (e.g., Dahlin, 2011), reading fluency (e.g., Luo et al., 2013; Shiran \& Breznitz, 2011), and phonological skills (e.g., Shiran \& Breznitz, 2011) in individuals with developmental dyslexia, and the transfer effects in the present study are consistent with these findings. The substantial positive changes in CR's reading comprehension scores indicate that our training protocol improved not only decoding processes but also comprehension skills. Given that WM operates differently in reading com- prehension and decoding (Arrington, Kulesz, Francis, Fletcher, \& Barnes, 2014) and the current treatment activities did not actively engage in or oblige any comprehension processing, general improvement in verbal WM, not specific to the tasks trained in the study may have contributed to CR's enhanced reading comprehension. Following treatment, $\mathrm{CR}$ also demonstrated improved sustained attention on the TEA. Such attention gains may also relate to his improved reading fluency and comprehension; in prior studies, sustained attention skills have been significantly correlated with or predicted word decoding and reading comprehension (Varvara et al., 2014), and deficits in sustained attention have been found to negatively impact reading comprehension (Arrington et al., 2014).

On the other hand, neither AR nor CR displayed improvements on timed subtests (e.g., Rapid Digit Naming and Rapid Letter Naming subtests of CTOPP) post-treatment, despite their reading gains. Performance on these timed tasks was not expected to improve because reading and working memory skills and strategies were the target of the current treatment, as opposed to processing speed. This selectivity of transfer effects observed in the current investigation may suggest that the observed WM and reading improvements were not attributable to nonspecific variables such as level of expectancy, motivation, or cognitive investment during treatment, but instead a product of practicing cognitive-linguistic activities and memory strategies. Moreover, participants correspondingly showed perceived benefits in their daily lives, particularly with respect to their perceptions of reading and writing, and their confidence.

It is important to note that the current cognitive-linguistic protocol included strategy training. Previously, the WM performance of children with reading disabilities has been found to benefit from strategy training (e.g., Swanson, Kehler, \& Jerman, 2010). Furthermore, in prior cognitive treatment studies, strategy training combined with direct intervention appeared a more effective approach to achieving treatment gains or transfer effects than direct intervention alone or strategy training alone among children and adults with or without disabilities (Cicerone et al., 2011; Ehlhardt et al., 2008; Murray, 2012). Also, in treatment we made explicit the tie between the cognitive-linguistic treatment tasks and daily activities. This component of the treatment may have yielded oppor- 
Eun Jin Paek, et al. • A Novel Cognitive-Linguistic Approach to Addressing Developmental Reading Disorders

tunities for participants to utilize their learned strategies and thus better address any challenging reading and writing tasks in their daily lives.

Thus far, maintenance of transferred gains (i.e., improved reading) has not been commonly measured in the previous WM training research for developmental reading disorders. In the current investigation, both $\mathrm{AR}$ and $\mathrm{CR}$ maintained their treatment gains on the probe tasks at the 6-week follow-up. Furthermore, on the standardized assessments, CR demonstrated maintenance of the near (i.e., improved verbal WM) as well as far transfer effects (i.e., enhancement in phonological processing, phonological awareness, reading fluency, and reading comprehension). These outcomes are consistent with those of Horowitz-Kraus and Breznitz (2009) who similarly reported that following WM training, college students with dyslexia showed maintenance effects up to 6 months. The cognitive strategy training in our treatment protocol may have contributed to the maintained gains of our participants given prior research supporting that strategy training promotes maintenance of treatment effects (O'Hara et al., 2007; Rebok et al., 2007).

The current pilot study has extended the developmental reading disorders treatment literature by examining the effects of a novel cognitive-linguistic treatment approach that used as training stimuli, real English words and sentences. In contrast, previous research studies investigating the effect of WM treatment on developmental reading disorders either focused on intervening only at the level of the phonological store (e.g., Maridaki-Kassotaki, 2002) or utilized as treatment stimuli either objects and isolated letters (Dahlin, 2011; Horowitz-Kraus \& Breznitz, 2009; Shiran \& Breznitz, 2011) or nonwords (Maridaki-Kassotaki, 2002). That is, few treatment studies for individuals with developmental reading problems thus far have utilized word- and/or sentence-level stimuli. Additionally, given the hypothetical dissociation between the store subsystems of WM and the central executive component, and the independent contribution of these systems to deficits in developmental dyslexia (Swanson, 1994), we speculated that utilizing tasks and stimuli designed to stimulate the phonological and articulatory buffer in combination with the central executive component of WM would be more likely to yield benefit than using tasks that target only one component of WM. Also in comparison to at least some prior interventions (e.g., Horowitz-Kraus \& Breznitz, 2009), our treatment stimuli and tasks were more similar to the everyday activities and problems that our participants encountered during their daily lives. The transfer and maintenance effects observed in the current study support the importance of training both central executive and phonological buffer to ameliorate WM and reading problems. The interaction between both components (i.e., phonological storage and processing) of WM and simultaneous incorporation of these aspects into reading interventions will need to be considered for future clinical research and practice. That is, in a treatment activity, combining the demands for repetition (for the phonological store) and manipulation (for the active processing) related to the reading process might produce results that can actually benefit individual's reading skills better than using only either of these components, but this contention requires a formal empirical investigation.

Lastly, from a theoretical perspective, although it has been argued that the core deficit in developmental reading disorders is phonological processing (e.g., Lyon et al., 2003), our data support the multiple deficit theory as the transfer effects were found in reading accuracy, fluency, and comprehension as well as phonological processing (Peterson \& Pennington, 2015). Thus, developmental reading problems, at least in our participants, are not likely due to a single source of deficit, but instead phonological processing may interact with other skills such as WM, and poor WM skills observed in this population or increased demands on WM may worsen the reading difficulties.

Given the number of cognitive constructs involved with completing the training tasks (e.g., linguistic processing, short term memory, attention, and WM in the Reading Span probe task), it remains unclear what component(s) improved by the treatment played a crucial role in producing near and far transfer effects, namely improved decoding, reading comprehension, and phonological processing. We used a compilation of several different WM treatment tasks involving linguistic stimuli in concert with strategy training to maximize training-related gains, generalization and transfer effects, and maintenance (Ehlhardt et al., 2008). Although such an approach obscures delineating which component of training and cognitive-linguistic benefits underlie or contributed to the observed gains, if only one WM training task was utilized, the complex nature of WM would similarly hinder identifying the specific WM mechanism(s) generating the treatment benefits (Morrison 
\& Chein, 2011).

It is possible that broader treatment effects were not observed due to the intervention schedule (Warren, Fey, \& Yoder, 2007): Participants in this study were able to attend only one treatment session per week for a total of 16-20 sessions, and the adolescent participant chose not to attend during school breaks. Thus, for further research, a more intensive treatment schedule and/or greater number of treatment sessions should be explored as a means to yield larger and broader gains. More intensive and longer access to treatment may be particularly valuable to individuals with broader deficits in reading and writing skills as well as WM. In terms of our study design, it should also be noted that participant CR had to travel a long distance to visit the study site, thus making it difficult to establish more than three baseline data points for him and consequently, achieve a staggered baseline across participants; furthermore, only two participants completed the study. Future studies should incorporate a staggered baseline for a stronger singlesubject design and replicate the treatment effects across a larger number of participants to further demonstrate the potency of this novel intervention method.

In conclusion, the findings in the current study support that a cognitive-linguistic stimulation treatment combined with strategy training can be a viable intervention option to ameliorate reading difficulties as well as WM deficits in adolescents and adults with developmental reading disorders. These results may assist in identifying and supporting potential clients who are more likely to respond to intervention approaches that target multiple cognitivelinguistic constructs versus an isolated component of reading or WM. Strategy training and inclusion of training tasks that resemble the complicated tasks encountered in daily life may provide more opportunities for transfer of treatment effects to realistic settings and daily activities. Finally, our cognitive-linguistic treatment approach yielded perceived benefits in addition to the maintenance of transfer effects, providing some guidance for evidencebased practice to clinicians working with adolescents and adults with developmental reading disorders.

\section{ACKNOWLEDGEMENT}

We would like to thank Dr. Megan Mahowald and Megan Lough- nane for their assistance with data collection, and our research participants for their participation in the study.

\section{REFERENCES}

Al Otaiba, S., \& Fuchs, D. (2006). Who are the young children for whom best practices in reading are ineffective? An experimental and longitudinal study. Journal of Learning Disabilities, 39, 414-431.

Alloway, T. P., Wootan, S., \& Deane, P. (2014). Investigating working memory and sustained attention in dyslexic adults. International Journal of Educational Research, 67, 11-17.

Arrington, C. N., Kulesz, P. A., Francis, D. J., Fletcher, J. M., \& Barnes, M. A. (2014). The contribution of attentional control and working memory to reading comprehension and decoding. Scientific Studies of Reading, 18, 325346.

Baddeley, A. (2003). Working memory and language: an overview. Journal of Communication Disorders, 36, 189-208.

Bear, D. R., Invernizzi, M., Templeton, S., \& Johnston, F. (2012). Words their way: word study for phonics, spelling, and vocabulary instruction (5th ed.). Upper Saddle River, NJ: Pearson.

Beeson, P. M., \& Robey, R. R. (2006). Evaluating single-subject treatment research: lessons learned from the aphasia literature. Neuropsychology Review, 16, 161-169.

Byiers, B. J., Reichle, J., \& Symons, F. J. (2012). Single-subject experimental design for evidence-based practice. American Journal of Speech-Language Pathology, 21, 397-414.

Chein, J. M., \& Morrison, A. B. (2010). Expanding the mind's workspace: training and transfer effects with a complex working memory span task. Psychonomic Bulletin \& Review, 17, 193-199.

Cicerone, K. D., Langenbahn, D. M., Braden, C., Malec, J. F., Kalmar, K., Fraas, M., ... \& Azulay, J. (2011). Evidence-based cognitive rehabilitation: updated review of the literature from 2003 through 2008. Archives of physical Medicine and Rehabilitation, 92, 519-530.

Conway, A. R., Kane, M. J., Bunting, M. F., Hambrick, D. Z., Wilhelm, O., \& Engle, R. W. (2005). Working memory span tasks: a methodological review and user's guide. Psychonomic Bulletin \& Review, 12, 769-786.

Dahlin, E., Bäckman, L., Neely, A. S., \& Nyberg, L. (2009). Training of the executive component of working memory: subcortical areas mediate transfer effects. Restorative Neurology and Neuroscience, 27, 405-419.

Dahlin, K. I. (2011). Effects of working memory training on reading in chil- 
Eun Jin Paek, et al. • A Novel Cognitive-Linguistic Approach to Addressing Developmental Reading Disorders

dren with special needs. Reading and Writing, 24, 479-491.

Daneman, M., \& Carpenter, P. A. (1980). Individual differences in working memory and reading. Journal of Verbal Learning and Verbal Behavior, 19, 450-466.

Delis, D., Kaplan, E. B., \& Kramer, J. (2001). The Delis-Kaplan executive function system. San Antonio, TX: The Psychological Corporation.

Duff, F. J., \& Clarke, P. J. (2011). Practitioner review: reading disorders: what are the effective interventions and how should they be implemented and evaluated? Journal of Child Psychology and Psychiatry, 52, 3-12.

Ehlhardt, L. A., Sohlberg, M. M., Kennedy, M., Coelho, C., Ylvisaker, M., Turkstra, L., \& Yorkston, K. (2008). Evidence-based practice guidelines for instructing individuals with neurogenic memory impairments: what have we learned in the past 20 years? Neuropsychological Rehabilitation, 18, 300342.

Goodman, R. A., \& Caramazza, A. (1985). The Johns Hopkins University dysgraphia battery. Baltimore, MD: Johns Hopkins University.

Hammill, D. D. (1998). Detroit tests of learning aptitude (4th ed.). Austin, TX: Pro-Ed.

Henk, W. A., Marinak, B. A., \& Melnick, S. A. (2012). Measuring the reader self-perceptions of adolescents: introducing the RSPS2. Journal of Adolescent \& Adult Literacy, 56, 311-320.

Horowitz-Kraus, T., \& Breznitz, Z. (2009). Can the error detection mechanism benefit from training the working memory? A comparison between dyslexics and controls: an ERP study. PloS One, 4, e7141.

Howard, D., \& Patterson, K. E. (1992). The Pyramids and Palm Trees Test: a test of semantic access from words and pictures. Windsor, UK: Thames Valley Test Company.

Jacobson, N. S., \& Truax, P. (1991). Clinical significance: a statistical approach to denning meaningful change in psychotherapy research. Journal of Consulting and Clinical Psychology, 59, 12-19.

Jaeggi, S. M., Buschkuehl, M., Perrig, W. J., \& Meier, B. (2010). The concurrent validity of the N-back task as a working memory measure. Memory, $18,394-412$.

Kibby, M. Y., \& Cohen, M. J. (2008). Memory functioning in children with reading disabilities and/or attention deficit/hyperactivity disorder: a clinical investigation of their working memory and long-term memory functioning. Child Neuropsychology, 14, 525-546.

Lawton, T., \& Shelley-Tremblay, J. (2017). Training on movement figureground discrimination remediates low-level visual timing deficits in the dorsal stream, improving high-level cognitive functioning, including at- tention, reading fluency, and working memory. Frontiers in Human Neuroscience, 11, 1-21.

Leslie, L., \& Caldwell, J. (1995). Qualitative Reading Inventory-II (QRI-II). New York, NY: HarperCollins College Publishers.

Loosli, S. V., Buschkuehl, M., Perrig, W. J., \& Jaeggi, S. M. (2012). Working memory training improves reading processes in typically developing children. Child Neuropsychology, 18, 62-78.

Luo, Y., Wang, J., Wu, H., Zhu, D., \& Zhang, Y. (2013). Working-memory training improves developmental dyslexia in Chinese children. Neural Regeneration Research, 8, 452-460.

Lyon, G. R., Shaywitz, S. E., \& Shaywitz, B. A. (2003). A definition of dyslexia. Annals of Dyslexia, 53, 1-14.

Manly, T., Robertson, I. H., Anderson, V., \& Nimmo-Smith, I. (1999). TEACh: the test of everyday attention for children. London: Harcourt Assessment.

Maridaki-Kassotaki, K. (2002). The relation between phonological memory skills and reading ability in Greek-speaking children: can training of phonological memory contribute to reading development? European Journal of Psychology of Education, 17, 63-73.

Mayer, J. F., \& Murray, L. L. (2002). Approaches to the treatment of alexia in chronic aphasia. Aphasiology, 16, 727-743.

Mayer, J. F., \& Murray, L. L. (2012). Measuring working memory deficits in aphasia. Journal of Communication Disorders, 45, 325-339.

Menghini, D., Finzi, A., Carlesimo, G. A., \& Vicari, S. (2011). Working memory impairment in children with developmental dyslexia: is it just a phonological deficity? Developmental Neuropsychology, 36, 199-213.

Morrison, A. B., \& Chein, J. M. (2011). Does working memory training work? The promise and challenges of enhancing cognition by training working memory. Psychonomic Bulletin \& Review, 18, 46-60.

Murray, L. L. (2012). Direct and indirect treatment approaches for addressing short-term or working memory deficits in aphasia. Aphasiology, 26, 317-337.

National Reading Panel, National Institute of Child Health, \& Human Development. (2000). Report of the National Reading Panel: teaching children to read: an evidence-based assessment of the scientific research literature on reading and its implications for reading instruction. Washington, DC: National Institutes of Health.

Nicholas, L. E., \& Brookshire, R. H. (1993). A system for quantifying the informativeness and efficiency of the connected speech of adults with aphasia. Journal of Speech, Language, and Hearing Research, 36, 338-350. 
O’Hara, R., Brooks III, J. O., Friedman, L., Schröder, C. M., Morgan, K. S., \& Kraemer, H. C. (2007). Long-term effects of mnemonic training in community-dwelling older adults. Journal of Psychiatric Research, 41, 585-590.

Parker, R. I., Vannest, K. J., Davis, J. L., \& Sauber, S. B. (2011). Combining nonoverlap and trend for single-case research: Tau-U. Behavior Therapy, 42, 284-299.

Peterson, R. L., \& Pennington, B. F. (2015). Developmental dyslexia. Annual Review of Clinical Psychology, 11, 283-307.

Rebok, G. W., Carlson, M. C., \& Langbaum, J. B. (2007). Training and maintaining memory abilities in healthy older adults: traditional and novel approaches. The Journals of Gerontology Series B: Psychological Sciences and Social Sciences, 62(Special_Issue_1), 53-61.

Reynolds, C. R., \& Voress, J. K. (2007). Test of Memory and Learning 2 (TO$M A L-2)$. Austin, TX: Pro-Ed.

Robertson, I. H., Ward, T., Ridgeway, V., \& Nimmo-Smith, I. (1994). The Test of Everyday Attention. San Antonio, TX: Psychological Corporation.

Robey, R. R., Schultz, M. C., Crawford, A. B., \& Sinner, C. A. (1999). Singlesubject clinical-outcome research: designs, data, effect sizes, and analyses. Aphasiology, 13, 445-473.

Semel, E. M., Wiig, E. H., \& Secord, W. (2003). CELF: clinical evaluation of language fundamentals. San Antonio, TX: The Psychological Corporation.

Shewhart, W. A. (1931). Economic control of quality of manufactured products. New York, NY: David Van Nostrand.

Shiran, A., \& Breznitz, Z. (2011). The effect of cognitive training on recall range and speed of information processing in the working memory of dyslexic and skilled readers. Journal of Neurolinguistics, 24, 524-537.

Sohlberg, M. M., Ehlhardt, L., \& Kennedy, M. (2005). Instructional techniques in cognitive rehabilitation: a preliminary report. Seminars in Speech and Language, 26, 268-279.

Swanson, H. L. (1994). Short-term memory and working memory: do both contribute to our understanding of academic achievement in children and adults with learning disabilities? Journal of Learning disabilities, 27, 34-50.

Swanson, H. L., Kehler, P., \& Jerman, O. (2010). Working memory, strategy knowledge, and strategy instruction in children with reading disabilities. Journal of Learning Disabilities, 43, 24-47.

Tate, R. L., Perdices, M., McDonald, S., Togher, L., \& Rosenkoetter, U. (2014). The design, conduct and report of single-case research: resources to improve the quality of the neurorehabilitation literature. Neuropsychological Rehabilitation, 24, 315-331.

Valdois, S., Bosse, M. L., Ans, B., Carbonnel, S., Zorman, M., David, D., \& Pellat, J. (2003). Phonological and visual processing deficits can dissociate in developmental dyslexia: evidence from two case studies. Reading and Writing, 16, 541-572.

Vallat, C., Azouvi, P., Hardisson, H., Meffert, R., Tessier, C., \& Pradat-Diehl, P. (2005). Rehabilitation of verbal working memory after left hemisphere stroke. Brain Injury, 19, 1157-1164.

Varvara, P., Varuzza, C., Padovano Sorrentino, A. C., Vicari, S., \& Menghini, D. (2014). Executive functions in developmental dyslexia. Frontiers in $\mathrm{Hu}$ man Neuroscience, 8, 120.

Wagner, R. K., Torgesen, J. K., Rashotte, C. A., \& Pearson, N. (2013). The Comprehensive Test of Phonological Processing 2 (CTOPP-2). Austin, TX: Pro-Ed.

Warren, S. F., Fey, M. E., \& Yoder, P. J. (2007). Differential treatment intensity research: a missing link to creating optimally effective communication interventions. Mental Retardation and Developmental Disabilities Research Reviews, 13, 70-77.

Wechsler, D. (1997). Wechsler memory scale (WMS-III). San Antonio, TX: The Psychological Corporation.

Wiederholt, J. L., \& Bryant, B. R. (2001). Gray oral reading tests. Austin, TX: Pro-Ed.

Winter, P. (1976). The bear and the fly. New York, NY: Crown Publishers.

Wright, H. H., \& Fergadiotis, G. (2012). Conceptualising and measuring working memory and its relationship to aphasia. Aphasiology, 26, 258-278.

Wulf, G., \& Shea, C. H. (2002). Principles derived from the study of simple skills do not generalize to complex skill learning. Psychonomic Bulletin \& Review, 9, 185-211. 
Eun Jin Paek, et al. • A Novel Cognitive-Linguistic Approach to Addressing Developmental Reading Disorders

\section{국문초록}

\section{발달성 읽기장애에 대한 인지언어적 중재 접근법: 예비 연구}

백은진 ${ }^{1} \cdot$ Laura L. Murray²

'The University of Tennessee Health Science Center, ${ }^{2}$ Western University

배경 및 목적: 작업 기억 훈련은 발달성 난독증을 가진 자들의 읽기능력 증진에 유익한 것으로 밝혀져 왔다. 그러나 언어 자극물을 작 업기억 훈련에 직접적으로 사용하는 것이 읽기능력 증진에 어떠한 영향을 미치는지는 알려진 바가 없다. 또한, 각 개인의 언어 및 인지적 능력이 중재 효과에 대해 어떠한 영향을 미치는지도 불분명하다. 따라서 본 연구에서는 언어 자극물을 사용하는 새로운 인지언어적 중 재 접근법의 효과에 대해 살펴보았다. 방법: 각 1 명의 청소년과 성인 남성이 단일대상연구 실험에 참가하였다. 피험자는 전략 훈련에 더 해, 6 가지의 구어 작업기억 과제를 사용하여 중재를 받았다. 중재 전후의 언어 및 인지능력과 일반화 효과를 검증하기 위해, 피험자들에 게 중재 전, 중재 직후, 그리고 중재 후 6주 뒤 일련의 공식검사를 시행하였다. 결과: 모든 피험자들이 훈련된 과제에서 수행력 향상을 보 였으나, 피험자에 따라 각기 다른 양식을 보였다. 일반화 및 유지 효과 또한 관찰되었는데, 해독능력, 유창성, 그리고 읽기이해능력이 증 진되었고, 주관적 효용 또한 보고되었다. 논의 및 결론: 본 연구 결과는 인지언어적 중재법이 발달성 난독증 증상에 효과가 있음을 뒷받 침하며, 발달성 읽기장애를 지닌 청소년 및 성인의 근거기반 중재를 위한 실증적 증거를 제공한다.

핵심어: 발달성 읽기장애, 중재, 작업기억, 언어 